\title{
Ethyl Glucuronide, Ethyl Sulfate and Acetone as Biomarkers for Alcohol Based Hand Sanitizers Chronic Exposure in Health Care Workers
}

\author{
Ghada N. Mansour ${ }^{1}$ and Dina S. El-rafey ${ }^{2}$ \\ ${ }^{1}$ Department of Forensic Medicine \& Clinical Toxicology. \\ ${ }^{2}$ Department of Community, Environmental and Occupational medicine Department. \\ Faculty of Medicine, Zagazig university, Zagazig, Egypt.
}

\begin{abstract}
Introduction: health care workers (HCWs) are exposed to alcohols during hand antisepsis by both dermal contact and inhalation. This study aimed to assess the ethanol and isopropanol (ISOP) absorption in HCWs due to alcohol based hand sanitizers (ABHSs) use in real work conditions and to characterize the highest measurable concentrations of ethyl glucuronide (EtG) and ethyl sulfate (EtS) that could be produced by ABHSs use in order to recommend appropriate threshold concentrations specific enough to eliminate the possibility of false positive results due to incidental exposures to ethanol in Egypt.

Subject and Methods: ethanol and ISOP absorption were assessed in 74 HCWs using ABHSs during regular 8-hours working shift through measuring urinary concentrations of ethanol and its metabolites ethyl glucuronide (EtG) and ethyl sulfate (EtS) before the ABHSs use and for the following 24 hours as well as blood ISOP and its metabolite acetone were measured before ABHSs use and at the end of 8-hours shift.

Results: the highest maximum median urinary ethanol $(8.75 \mathrm{mg} / \mathrm{L})$, EtG $(538.93 \mathrm{ng} / \mathrm{mL})$ and EtS $(62 \mathrm{ng} / \mathrm{mL})$ as well as blood ISOP $(4.9 \mathrm{mg} / \mathrm{L})$ and acetone $(6.32 \mathrm{mg} / \mathrm{L})$ concentrations were recorded in group III (excessive ABHSs use), all these parameters returned to base line within 24 hours. Parameters were correlated to frequency, quantity of ABHSs used. EtG was correlated positively to the concentration of ethanol in ABHSs.

Conclusion: ABHSs use generated measurable levels of ethanol, EtG and EtS in urine as well as ISOP and acetone in blood. their concentrations decrease to baseline levels within 24 hours (not accumulated). EtG cut off of $1000 \mathrm{ng} / \mathrm{ml}$ and EtS cut off 100ng/ml seemed to be more promising in identification of incidental alcohol use in HCWs. Measuring EtS with EtG might be useful in incidental ethanol exposure.
\end{abstract}

Key words $\quad$ ABHSs, Ethyl glucuronide, Ethyl sulfate, Isopropanol, Ethanol.

\section{Introduction}

TT and hygiene products are heavily used in everyday life (Chan \& Chan, 2018) especially in the healthcare setting where the routine use of such products is a major aspect of modern infection control procedures (Bolon, 2016).

Alcohol-based hand sanitizers (ABHSs) are always preferred because of its greater effectiveness (Centre for Health Protection, 2017). Since ABHSs mostly contain ethanol, iso-propyl alcohol (ISOP), npropyl alcohol, or their combinations (Pires et al., 2017), the health care workers (HCWs) are exposed to the applied alcohols during hand antisepsis not only by dermal contact, but also by inhalation (Arndt et al., 2014).
Concerns about high alcohols absorption have been raised that may adversely affect HCWs (WHO, 2009). In the 2015, FDA indicated that, their administrative record for the safety of ABHSs is incomplete with respect to the human pharmacokinetic studies under maximal use conditions when applied topically and the effect of formulation on dermal absorption (Maier et al. 2015).

Alcohols biomarkers are physiological indicators of alcohol exposure, among the available direct biomarker are ethyl glucuronide (EtG) and ethyl sulfate (EtS) which are minor non-oxidative direct biomarkers of ethanol (SAMHSA, 2012).

Ethyl glucuronide (EtG) and ethyl sulfate (EtS) are usually measured in urine and become 
positive shortly after exposure to alcohol and may remain detectable in urine for 1 to 2 days (Litten et al., 2010).

During past years most data on alcohols absorption after hand antisepsis were obtained from standardized experimental studies under controlled conditions (Gessner et al., 2016), assessing only ethanol or propanols absorption but not in real exposure during regular work where health care workers use mixed ABHSs made up of at least two different alcohols, typically ethanol and ISOP (Bessonneau et al.,2010).

\section{Aim of the work}

This study aimed to: first; to assess the ethanol and ISOP absorption in HCWs following frequent application of two ABHSs containing ethanol and ISOP in two different concentrations during regular 8hours working shift through measuring serial urinary concentrations of ethanol and its metabolites EtG and EtS at the beginning of an 8-hours working shift and every 2 hours for the following 24 hours and measuring ISOP and its metabolite acetone in blood at the beginning and at the end of 8-hours working shift and the relation of these parameters to the frequency, quantity and alcohols concentrations of ABHSs used. Second; to characterize the highest measurable concentrations of EtG and EtS that could be produced by ABHSs use in order to recommend appropriate threshold concentrations specific enough to eliminate the possibility of false positive results due to incidental exposures to ethanol in Egypt.

\section{Subjects and methods}

\section{1- Study design:}

A comparative cross sectional study was conducted on 74 HCWs in private hospitals and clinics in CairoEgypt during the period from June 2016 to June 2018. Previously arranged semi structured interview was conducted with all participants in their workplace to fill a designed questionnaire. Participants were instructed to refrain from any ethanol intake or use as well as household disinfectants 24 hours before the study day and for the next 48 hours after repeatedly using ABHSs during a single 8-hour working shift. Prohibition of alcohol intake included consumption of alcoholic beverages, grape juice, apple juice, malt beer or alcohol-free beer, nonalcoholic energy drinks, and the use of alcohol-containing cosmetics such as aftershave, mouthwash, eye makeup remover, shave lotions, and ethanol-based aerosol product.

- Sample size calculation: it was calculated using Open-Epi according to the following; the mean value of urinary ethanol among low users was $1.53 \pm 0.65$ and among excessive users was $1.95 \pm 0.5$, so at power of study $80 \%$ and CI $95 \%$ the sample size was calculated to be 60 users, 30 as low users and 30 as excessive users. Another 14 subjects with intermediate user were chosen as a confirmative of the relation between the measured parameters and both the frequency and amount of ABHSs used. Therefore, the total subjects were 74 HCWs.

\section{2- Data Collection:}

A structured questionnaire was used, based on those of other relevant studies and also guidelines on Hand Hygiene in Health Care (WHO, 2009). The questionnaire composed of three main parts:

- Socio-demographic and occupational data: age, sex, weight, education, residence, marital status, pregnancy or lactation in female, medical history, special habits, prescribed medication usage, Usage of alcohol containing cosmetics and its frequency, duration of work, working days/weak, working hours /day.

- $\quad$ Professional practice data: the type of hand sanitizer frequently used, frequency of use/working hours, amount/use, frequency of hand wash/ working hours, usage of waterproof coverage of wounded skin, eating and drinking at workplace and the use of neutral $\mathrm{pH}$ soap before eating or drinking.

- Symptoms related to hand sanitizers use: respiratory tract irritation (cough, sneezing and chest tightness) and skin irritation (redness, dryness, itching, cracking, and bleeding).

- Ventilation of work place: existence of odors more than 10 minutes after use, strong odors away from the source, remaining of product odors in the morning in working place and presence of air conditions or extractors.

\section{3- Subjects:}

Seventy-four healthy HCWs were chosen to be involved in this study according to the data collected from the questionnaire, they had the same working hours (8 hours/shift) and working days (6 days/week), with matched socio-economic standard and nutritional habits and nonsmokers with no special habits.

Exclusion criteria:

- History of ethanol use disorder.

- Obsessive-compulsive disorder involving hand washing.

- Hepatic or renal dysfunction, diabetes mellitus, and symptoms of urinary tract infection.

- Pregnant or lactating women.

- Usage of alcohol containing cosmetics or medications in any form within 24 hours before or on the day of the study.

- Positive first urine specimen withdrawn before ABHSs use for EtG and EtS (>500 $\mathrm{ng} / \mathrm{mL}$ and $100 \mathrm{ng} / \mathrm{mL}$ respectively) (Andresen et al., 2018).

All participants were informed about the study aim and research design. An informed consent was obtained from those who agree to participate. Reassurance of confidentially was confirmed. All data were documented by a code, rather than participant's name.

- According to mood of use, subjects were divided into 3 groups:

Group I (low use group): including $30 \mathrm{HCWs}$ with mild use of ABHSs (10-19 times /shift).

Group II (intermediate use group): including 14 HCWs with moderate use of ABHSs (20-29 times /shift).

Group III (excessive use group): including $30 \mathrm{HCWs}$ with excessive use of ABHSs ( $\geq 30$ times /shift). 
- According to ABHSs used, subjects were divided into 2 groups:

Group A: including $37 \mathrm{HCWs}$ using ABHSs type A.

Group B: including $37 \mathrm{HCWs}$ using ABHSs type B.

4- Hand rubs used:

Two commercially hygienic hand rubs were found to be commonly used by participants and were tested in this study:

- Hand rub A: consists of ethanol $80 \%$ and ISOP $45 \%$.

- Hand rub B: consists of ethanol $65 \%$ and ISOP $60 \%$.

The hand rubs did not contain any fragrance or dye but a mixture of skin care components.

\section{5- Methods:}

\section{- Sample collection:}

A) Blood samples collection:

ISOP and its metabolite acetone were measured in HCWs' blood before the first use of ABHSs and at the end of 8-hour working shift. Five $\mathrm{ml}$ of peripheral venous blood in EDTA tube were taken from HCWs under complete aseptic conditions. Skin antisepsis was performed with an alcohol-free skin antiseptic (7.5\% povidone-iodine solution). Blood samples were stored at $-4^{\circ} \mathrm{C}$ and were processed within 12 hours of collection.

B) Urine samples collection:

Ethanol and its metabolites EtG and EtS were measured in HCWs' midstream urine obtained before any ABHSs exposure and every two hours until the following 24 hours. HCWs collected their urine samples themselves and noted the time of passing urine on each sample. To exclude subsequent enzyme activity samples were protected from sunlight by collecting them in polystyrene boxes and stored at $4^{\circ} \mathrm{C}$ up to a maximum of 24 hours (Baranowski et al., 2008 and Helander et al., 2007).

\section{- Procedures:}

A. Chemical analysis of ethanol, ISOP and acetone concentrations in biological samples:

Analysis was performed using Gas Chromatography (GC) in a modification of the method described by Roemhild et al. (1998)

\section{- Sample preparation:}

One $\mathrm{mL}$ of sample (blood for ISOP and acetone or urine for ethanol) or standard and $0.5 \mathrm{~g}$ of anhydrous Na2SO4 were filled in 1.5-mL head space vials and incubated for 45 minutes at $75^{\circ} \mathrm{C}$, then $2.5 \mathrm{~mL}$ was injected directly into GC with time interval of 0.5 minute.

\section{- Instruments and GC conditions:}

Gas chromatography (modification of Römhild by Head-space injection with flame-ionization detection). The chromatographic conditions were an injector temperature of $150^{\circ} \mathrm{C}$, a detector temperature of $250^{\circ} \mathrm{C}$, a column temperature program of $40^{\circ} \mathrm{C}$ for 8 minutes, followed by a ramp of $3^{\circ} \mathrm{C} /$ minute to $120^{\circ} \mathrm{C}$ ( 0 minutes) and then $30^{\circ} \mathrm{C} /$ minute to $230^{\circ} \mathrm{C}$ (5 minutes). Nitrogen (5.0) served as the carrier gas at a rate of $1.45 \mathrm{~mL} /$ minute $(21.9 \mathrm{~cm} / \mathrm{s})$.

- Linearity and calibration:
For each measurement, calibration was performed according to the method of the external standard with 3 calibration points (Medidrug BGS-S, levels 1-3; Medichem, Steinenbronn, Germany) and custom-made standards in water which were used for control standards. The method's detection limits were 0.14 $\mathrm{mg} / \mathrm{L}$ for ethanol, $0.03 \mathrm{mg} / \mathrm{L}$ for ISOP, and $0.01 \mathrm{mg} / \mathrm{L}$ for acetone. For all measurements, quality controls were performed using certified reference material (Medidrug BGS 2/05 S-Plus; Medichem). Calibration with external or self-made standard was needed if the sample concentration did not lie in the calibration level. b. Chemical analysis of EtG and EtS concentrations in urine:

EtG and EtS quantitation in subjects' urine samples was performed using high-performance liquid chromatography tandem mass spectrometry (LC-MSMS) instrument according to Albermann et al., (2012).

\section{- Chemical and reagents:}

EtG/EtS and d5-EtG/d5-EtS (Lipomed, Arlesheim, Switzerland), Methanol, acetonitrile, and formic acid (98\%) (Merck, Darmstadt, Germany). Water was purified with a NANO pure Diamond Analytic Water Purification System D11901 (Barnstead, Dubuque, IA). Stock solutions of EtG and EtS (both $1 \mathrm{~g} / \mathrm{L}$ ) as well as of d5-EtG and d5-EtS (both $5 \mathrm{~g} / \mathrm{L}$ ) were prepared in methanol by weighing separately. All solutions were stored at $-20 \mathrm{C}$. Standards used for calibration were prepared by spiking blank urine at $0.025,0.05,0.1$, $0.25,0.5,1$, and $2 \mathrm{mg} / \mathrm{L}$. Quality control samples were prepared at $0.1,0.35,0.5$, and $1.5 \mathrm{mg} / \mathrm{L}$. All working solutions were stored in a refrigerator $\left(2-8^{\circ} \mathrm{C}\right)$.

\section{- Sample preparation:}

For protein precipitation, $20 \mu \mathrm{L}$ of the internal standard [methanolic solution of d5-EtG and d5-EtS (both 2.5 $\mu \mathrm{L} / \mathrm{mL})]$ and $280 \mu \mathrm{L}$ methanol were added to a 100 $\mu \mathrm{L}$ urine sample. The samples were vortexed for a short time and centrifuged (12,000 rpm for $5 \mathrm{~min}$ ). Then $300 \mu \mathrm{L}$ of the supernatant were separated and evaporated to dryness under a stream of nitrogen at $40^{\circ} \mathrm{C}$. The dried extracts were reconstituted with 600 $\mu \mathrm{L}$ of $0.1 \%$ aqueous formic acid and $10 \mu \mathrm{L}$ aliquots were injected directly into injected into LC-MS-MS.

- Instruments and LC-MS-MS conditions:

Analyses were performed on a Shimadzu LC-20A Series system (Shimadzu, Duisburg, Germany) interfaced to a 4000 Q-Trap (Applied Biosystems/Sciex, Darmstadt, Germany) with an electrospray Turbo V Ion source in negative mode. The ESI source settings were: ion-spray voltage, - $4500 \mathrm{~V}$; source temperature, $4508 \mathrm{C}$; nebulation and heating gas, (N2), 60 psi and 50 psi, respectively. A mobile phase of water containing $0.1 \%$ of formic acid (solvent A) and acetonitrile (solvent $\mathrm{B}$ ) was used with a flow rate of $0.2 \mathrm{~mL} / \mathrm{min}$, and the following gradient program was used: $100 \%$ A for 6 min; switch to $100 \%$ B over 1 min and hold for 2 min; back to $100 \%$ A over 1 min and hold for $4 \mathrm{~min}$. Using a tee mixer, acetonitrile was added post-column $(0.1 \mathrm{~mL} / \mathrm{min})$ to enhance analyte ionization. Detection of the ions was performed in multiple reaction monitoring (MRM) mode, using the following precursor to product ion transitions: EtG 221/75 (target), 221/85 (qualifier 1), 221/113 (qualifier 
2); d5-EtG: 226/85 (target), 226/75 (qualifier); EtS 125/97 (target), 125/ 80 (qualifier 1), 125/64 (qualifier 2); d5-EtS: 130/98 (target), and 130/ 80 (qualifier). The expected relative peak areas of the transitions for EtG and EtS are: 221/75:221/85:221/113 100:100:60 and 125/ 97:125/80:125/64 100:30:1, respectively. Analysis of the collected data was carried out with Analyst software (Version 1.4.2, Applied Biosystems/Sciex, Darmstadt, Germany).

- Linearity and calibration:

Calibration was evaluated by analyzing six replicates of spiked urine samples with EtG and EtS at 0.025, $0.05,0.1,0.25,0.5,1.0$, and $2.0 \mathrm{mg} / \mathrm{L}$. Based on the EtG/EtS calibrator, concentrations at $0.010,0.015$, $0.020,0.025$, and $0.030 \mathrm{mg} / \mathrm{L}$ were used; the limits of detection (LOD) and the limits of quantitation (LOQ) were calculated according to the German Industrial norm DIN 32645.The results were: EtG $0.005 \mathrm{mg} / \mathrm{L}$ (LOD) and $0.019 \mathrm{mg} / \mathrm{L}$ (LOQ) and EtS $0.005 \mathrm{mg} / \mathrm{L}$ (LOD) and $0.015 \mathrm{mg} / \mathrm{L}$ (LOQ).

To minimize the physiological variations in urinary excretion, creatinine was measured by the Jaffe method using an Abbott Architect instrument (Abbott Laboratories, Abbott Park, IL, USA), and every EtG and EtS levels was normalized with respect to 100 $\mathrm{mg} / \mathrm{dL}$ of excreted creatinine (Dahl et al., 2002 and Goll et al., 2002).

- Statistical analysis:

The collected data were computerized and statistically analyzed using SPSS program (Statistical Package for Social Science) version 25.0. Qualitative data were represented as frequencies and relative percentages. Chi square test was used to calculate difference between qualitative variables. Quantitative data were expressed as mean \pm SD (Standard deviation), median and interquartile range (IQR). Mann Whitney test was used to calculate difference between quantitative variables in two groups in not normally distributed data. ANOVA test (F) was used to calculate difference between quantitative variables in more than two groups in normally distributed data and Kruskal Wallis test (K) in not normally distributed data. Post hook LSD used to compare between groups. Spearman's correlation coefficient (r) was used to calculate correlation between different quantitative variables. Results considered to be significant when p value < 0.05 and highly significant when $p$ value $<0.01$.

\section{Results}

1. Demographic data of the participants:

Seventy-four healthy participants were chosen to be involved in this study with the following demographic data:

- Age: aged from 25-46 years.

- Sex: 38 females and 36 males.

- Occupation: 14 laboratory staff members, 15

surgeons, 15 dentists, 19 nurses, and 11 pediatricians.

- Weight: weigh from 64-95 Kg.

- Working period: from 1-15 years.

- Working 8 hours/shift for 6 shifts/week.

There were a non-significant differences as regard the previously mentioned items between the all groups.
The mean values of the frequency of ABHSs use/8 hours shift and the amount of ABHSs/ each use in the three groups is shown in table (1). A highly significant differences were found between the three groups with a highly significant increase in group III when compared to both group I and II as regard the frequency of ABHSs use/8 hours shift (table 1). There was a nonsignificant difference between both groups $A$ and $B$ as regard the previous two parameters $(p=0.32, p=0.58$ respectively).

As regard the respiratory and dermal symptoms related to ABHSs use, there was a highly significant difference between the three groups as regard respiratory symptoms with a significant increase in group III in comparison to group I and II, while a non-significant difference was found as regard dermal symptoms. When group A and B were compared to each other, a non-significant difference was found as regard respiratory symptoms, and a highly significant increase in group B as regard dermal symptoms as shown in table (2).

\section{Results of serial urinary ethanol concentrations:}

The median baseline urinary ethanol concentration in HCWs was $0.09 \pm 0.05 \mathrm{mg} / \mathrm{L}$ (IQR 0.06-0.13 mg/L), the urinary ethanol concentration increased starting from the $2^{\text {nd }}$ hour after baseline until the $8^{\text {th }}$ hour when the maximum values were recorded with medians of $3.84 \mathrm{mg} / \mathrm{L}$ (IQR, 3.56-3.99 mg/L) in group I, 6.21mg/L (IQR, 5.94-6.54 mg/l) in group II and $8.75 \mathrm{mg} / \mathrm{L}$ (IQR, 7.85-8.96 $\mathrm{mg} / \mathrm{L}$ ) in group III with a highly significant difference in-between $(\mathrm{F}=$ 226.82, $p<0.001$ ). A highly significant increase in group III was found when compared to both groups I $(p<0.001)$ and II $(p<0.001)$. At $10^{\text {th }}$ hour, the median urinary ethanol concentrations started to decrease until stabilization at $16^{\text {th }}$ hour (fig. 1). When both groups $\mathrm{A}$ and $\mathrm{B}$ were compared to each other as regard urinary ethanol level, a non-significant difference was recorded with MW=1.64 and $p=0.10$.

\section{Results of serial urinary EtG concentrations:}

The base line urinary EtG concentration were below the detection limits in all participants. It started to increase from the $2^{\text {nd }}$ hour until the $12^{\text {th }}$ hour at which the maximum values were recorded with medians of $214 \mathrm{ng} / \mathrm{ml}$ (IQR, 172-546.5 ng/mL in group I), 462.29 $\mathrm{ng} / \mathrm{mL}$ (IQR, 371.75-563.5 $\mathrm{ng} / \mathrm{mL}$ ) in group II and $538.93 \mathrm{ng} / \mathrm{mL}$ (IQR, 423-756 ng/mL) in group III with a highly significant difference between them $(K=21.17$, $p<0.001)$. There was a highly significant increase in group III when compared to both groups I $(p<0.001)$ and II $(p=0.05)$. When group I and 1I were compared to each a significant difference was found $(p=0.008)$. At $14^{\text {th }}$ hour, the median urinary EtG concentrations started to decrease continuously until stabilization at $24^{\text {th }}$ hour as shown in fig. 2 . When both groups A and $\mathrm{B}$ were compared to each other, a significant difference was found between the two groups with $\mathrm{MW}=1.95$ and $p=0.05$ (median=512 ng/mL and IQR, 320-642 ng/mL in group A, median = 398 and IQR, 212-538 in group B). 


\section{Results of serial urinary EtS} concentrations:

The base line urinary EtS concentration were below the detection limits in all participants. It started to increase from the $2^{\text {nd }}$ hour until the $12^{\text {th }}$ hour at which the maximum values were recorded with medians of $27.5 \mathrm{ng} / \mathrm{mL}$ (IQR, 0-68 ng/mL) in group I, 66.7 $\mathrm{ng} / \mathrm{mL}$ (IQR, 0-77.5 ng/mL) in group II and $68 \mathrm{ng} / \mathrm{mL}$ (IQR, 59-78.25 ng/mL) in group III respectively with a highly significant difference between them $(\mathrm{K}=11.02$, $\mathrm{p}=0.004)$. There was a highly significant increase in group III when compared to both groups I $(p<0.001)$ and II $(p=0.05)$. When group I and 1I were compared to each a non-significant difference was found $(p=0.07)$. At 14 th hour, the median urinary EtS concentrations started to decrease continuously until stabilization at 24th hour (fig. 3). When both groups $\mathrm{A}$ and $\mathrm{B}$ were compared to each other, a nonsignificant difference was recorded (MW=59, $p=0.65)$.

5. Results of blood ISOP and acetone concentrations:

The participants medians baseline concentrations of blood ISOP and means of acetone were recorded in table (3). At the $8^{\text {th }}$ hour, both blood ISOP and acetone concentrations increased in the three groups with a highly significant difference between them (table 3 \& fig. 4). There was a highly significant increase in group III when compared to both groups I and II. When group I and II were compared to each a non-significant difference was found as shown in table (3). When both groups $\mathrm{A}$ and $\mathrm{B}$ were compared to each other, no significant difference was found.

The urinary ethanol and its metabolites EtG and EtS levels were positively correlated to the frequency of use of ABHSs with $r=0.924 \& p<0.001, r=0.523 \& p<$ 0.001 and $r=0.352 \& p=0.002$ respectively. As well as to the amount of ABHSs used with $r=0.510 \& p<0.001$, $r=0.288 \& p<0.013$ and $r=0.306 \& p=0.008$. A positive correlation was found between blood ISOP levels and the amount of ABHSs used $(r=0.284 \&$ $p=0.014$ ) and a negative correlation to the frequency of ABHSs used ( $\mathrm{r}=0.149 \& p=0.206)$. On the other hand, a positive correlation was found between blood acetone levels and the frequency of ABHSs used $(r=0.357 \&$ $p=0.002)$ and a negative correlation to the amount of ABHSs used $(\mathrm{r}=0.219 \& p=0.61)$.

Table 1: Statistical analysis by one way Anova and LSD tests between means of frequency and amount of ABHSs/8 hours shift in group I, II and III

\begin{tabular}{|l|l|l|l|l|c|}
\hline \multicolumn{1}{|c|}{ Item } & Groups & Mean \pm SD & F & P & Post Hoc LSD test \\
\hline Frequency/ 8 hours shift (n) & Group I & $16.23 \pm 2.16$ & & & $<0.001^{* * 1}$ \\
& Group II & $24.43 \pm 3.16$ & 339.9 & $0.001^{* *}$ & $<0.001^{* * 2}$ \\
& Group III & $33.90 \pm 2.78$ & & & $<0.001^{* * 3}$ \\
\hline Amount of ABHS/ one use (m) & Group I & $9.83 \pm 3.82$ & & & $0.306^{01}$ \\
& Group II & $8.57 \pm 3.63$ & 23.6 & $0.001^{* *}$ & $<0.001^{* * 2}$ \\
& Group III & $15.50 \pm 3.79$ & & & $<0.001^{* * 3}$ \\
\hline
\end{tabular}

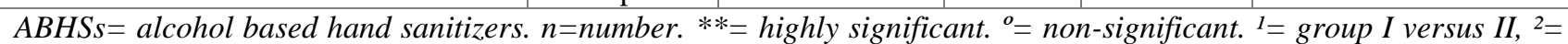
group II versus III, ${ }^{3}=$ group I versus III. F= Anova test. $S D=$ standard deviation.

Table 2: Statistical analysis by Chi-squared and LSD tests between HCWs in group I, II and III as well as between HCWs in group $A$ and $B$ as regard respiratory and dermal symptoms related to ABHSs use:

\begin{tabular}{|c|c|c|c|c|c|c|c|c|c|c|c|c|}
\hline \multirow{2}{*}{\multicolumn{2}{|c|}{\begin{tabular}{|l|} 
Symptoms \\
\end{tabular}}} & \multicolumn{3}{|c|}{ Groups } & \multirow{2}{*}{$\chi^{2}$} & \multirow{2}{*}{$\boldsymbol{P}$} & \multirow[b]{2}{*}{$\begin{array}{c}\text { Post } \\
\text { Hoc } \\
\text { LSD } \\
\text { test }\end{array}$} & \multicolumn{2}{|c|}{ Groups } & \multirow{2}{*}{$\chi^{2}$} & \multirow{2}{*}{$\boldsymbol{P}$} & \multirow[b]{2}{*}{ Post Hoc LSD tes } \\
\hline & & $\begin{array}{c}I \\
(t=30)\end{array}$ & $\underset{(t=14)}{\text { II }}$ & $\underset{(t=30)}{\text { III }}$ & & & & $\begin{array}{c}A \\
(t=37)\end{array}$ & $\begin{array}{c}B \\
(t=37)\end{array}$ & & & \\
\hline $\begin{array}{l}\text { Respiratory } \\
\text { symptoms }\end{array}$ & $\begin{array}{l}\mathrm{n} \\
\%\end{array}$ & $\begin{array}{c}12 \\
40 \%\end{array}$ & $\begin{array}{c}7 \\
50 \%\end{array}$ & $\begin{array}{c}24 \\
80 \%\end{array}$ & $\begin{array}{c}0.39 \\
10 \\
4.13\end{array}$ & $0.03 *$ & $\begin{array}{c}0.53^{\circ 1} \\
0.002^{* * 2} \\
0.04^{* 3}\end{array}$ & $\begin{array}{c}20 \\
54.1 \%\end{array}$ & $\begin{array}{c}23 \\
62.2 \%\end{array}$ & 0.50 & $0.48^{\circ}$ & NS \\
\hline $\begin{array}{l}\text { Dermal } \\
\text { Symptoms }\end{array}$ & $\begin{array}{l}\mathrm{n} \\
\%\end{array}$ & $\begin{array}{c}17 \\
56.7 \%\end{array}$ & $\begin{array}{c}7 \\
50.0 \%\end{array}$ & $\begin{array}{c}19 \\
63.3 \%\end{array}$ & $\begin{array}{l}0.17 \\
0.28 \\
0.70 \\
\end{array}$ & $0.3^{\circ}$ & NS & $\begin{array}{c}16 \\
43.2 \%\end{array}$ & $\begin{array}{c}27 \\
73 \%\end{array}$ & 6.72 & $0.01 *$ & $\begin{array}{c}0.02^{* 1} 0.04^{* 2} \\
0.001^{* * 3}\end{array}$ \\
\hline
\end{tabular}

$n=$ number. $m l=$ milliliters. $^{*}=$ significant. $^{* *}=$ highly significant. $^{o}=$ non-significant. ${ }^{1}=$ group I versus II, ${ }^{2}=$ group II versus III, ${ }^{3}=$ group $I$ versus III. $F=$ Fisher's Exact test. $S D=$ standard deviation. $\chi^{2}=$ Chi-squared test. NS= not significant. 
Table 3: Statistical analysis using Kruskal Wallis, ANOVA and Post-hoc tests of medians and IQR blood ISOP and means acetone concentrations before and 8 hours after ABHSs use in group I, II and III:

\begin{tabular}{|c|c|c|c|c|c|c|c|c|}
\hline Item & Group & Mean \pm SD & Median & IQR & Range & Test & $\boldsymbol{P}$ & $\begin{array}{l}\text { Post Hoc } \\
\text { LSD test }\end{array}$ \\
\hline $\begin{array}{c}\text { ISOP } \\
\text { Before ABHSs } \\
\text { use }\end{array}$ & $\begin{array}{l}\text { group I } \\
\text { group II } \\
\text { group III }\end{array}$ & $\begin{array}{c}0.09 \pm 0.18 \\
0.047 \pm 0.066 \\
0.07 \pm 0.07\end{array}$ & $\begin{array}{c}0.05 \\
0 \\
0.05\end{array}$ & $\begin{array}{l}0-0.09 \\
0-0.12 \\
0-0.14\end{array}$ & $\begin{array}{c}0-0.9 \\
0-0.15 \\
0-0.18 \\
\end{array}$ & $\begin{array}{c}\mathrm{K} \\
1.53\end{array}$ & $0.47^{\circ}$ & ---- \\
\hline $\begin{array}{c}\text { ISOP } \\
8 \text { h after start of } \\
\text { ABHSs use }\end{array}$ & $\begin{array}{l}\text { group I } \\
\text { group II } \\
\text { group III }\end{array}$ & $\begin{array}{l}3.73 \pm 1.36 \\
3.74 \pm 1.64 \\
4.71 \pm 1.28\end{array}$ & $\begin{array}{c}3.96 \\
3.53 \\
4.9\end{array}$ & $\begin{array}{c}2.56-4.78 \\
2.43-5.03 \\
4.2-5.68\end{array}$ & $\begin{array}{c}1.35-6.15 \\
1.05-6.78 \\
1.5-6.15\end{array}$ & $\begin{array}{c}\mathrm{K} \\
9.72\end{array}$ & $0.008^{* *}$ & $\begin{array}{c}0.82^{\circ 1} \\
0.003^{* * 2} \\
0.046^{* 3}\end{array}$ \\
\hline $\begin{array}{c}\text { aceton } \\
\text { Before ABHSs } \\
\text { use }(\mathrm{mg} / \mathrm{l})\end{array}$ & $\begin{array}{l}\text { group I } \\
\text { group II } \\
\text { group III }\end{array}$ & $\begin{array}{l}1.91 \pm 0.38 \\
1.88 \pm 0.36 \\
1.78 \pm 0.51\end{array}$ & $\begin{array}{l}1.99 \\
1.97 \\
1.58\end{array}$ & $\begin{array}{l}1.58-2.08 \\
1.57-2.08 \\
1.45-2.14\end{array}$ & $\begin{array}{c}1.25-2.78 \\
1.2-2.5 \\
1.05-2.86\end{array}$ & $\begin{array}{c}F \\
0.77\end{array}$ & $0.47^{\circ}$ & ------ \\
\hline $\begin{array}{c}\text { aceton } \\
\text { 8h after start of } \\
\text { ABHSs use ( } \\
\text { mg/l) }\end{array}$ & $\begin{array}{l}\text { group I } \\
\text { group II } \\
\text { group III }\end{array}$ & $\begin{array}{l}5.64 \pm 1.10 \\
6.10 \pm 1.01 \\
6.84 \pm 0.71\end{array}$ & $\begin{array}{l}5.53 \\
6.56 \\
6.23\end{array}$ & $\begin{array}{c}4.65-6.65 \\
5.41-6.58 \\
6.23-7.5\end{array}$ & $\begin{array}{l}3.87-7.56 \\
4.04-7.89 \\
5.89-8.58\end{array}$ & $\begin{array}{c}F \\
12.30\end{array}$ & $0.003^{* *}$ & $\begin{array}{c}0.14^{\circ 1} \\
0.001^{* * 2} \\
0.017^{* 3}\end{array}$ \\
\hline
\end{tabular}

*= Significant. ${ }^{* *}=$ highly significant. ${ }^{o}=$ non-significant. ${ }^{1}=$ group I versus II, ${ }^{2}=$ group II versus III, ${ }^{3}=$ group I versus III. $F=$ Anova test. $S D=$ standard deviation. $K=$ Kruska-Wallis test.

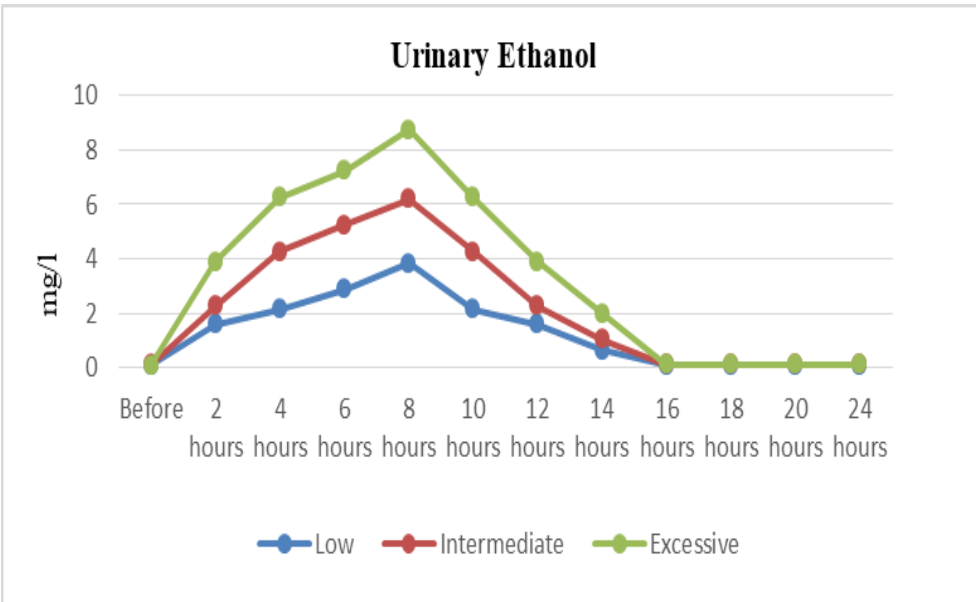

Fig.1: Kinetic of urinary ethanol concentrations before and for 24 hours after ABHSs use in the three groups (low= group I, intermediate $=$ group II, excessive $=$ group III).

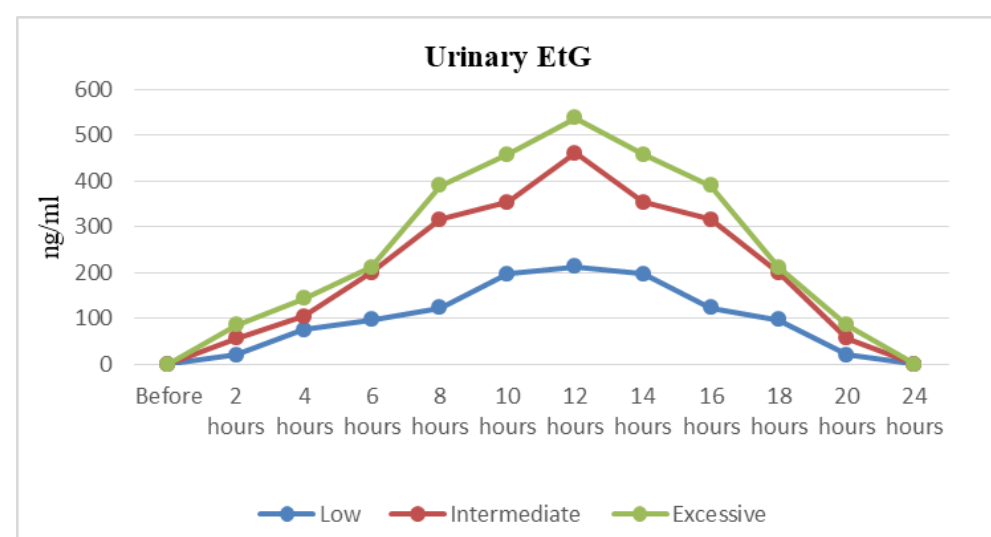

Fig.2: Diagram showing the kinetic of urinary EtG concentrations before and for 24 hours after ABHSs use in the three groups (low= group I, intermediate $=$ group II, excessive $=$ group III). 


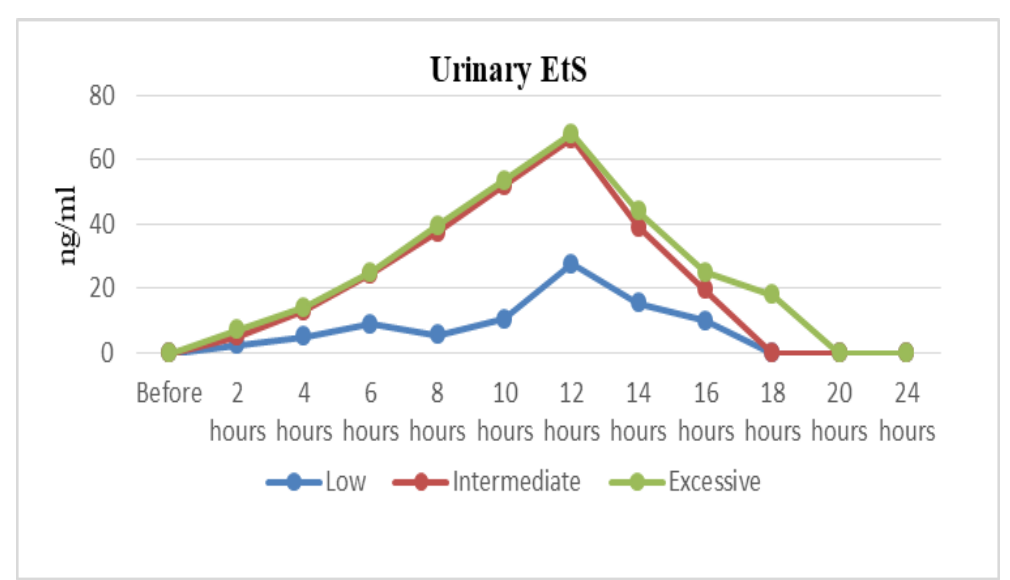

Fig.3: Diagram showing the kinetic of urinary EtS concentrations before and for 24 hours after ABHSs use in the three groups (low= group I, intermediate $=$ group II, excessive $=$ group III).

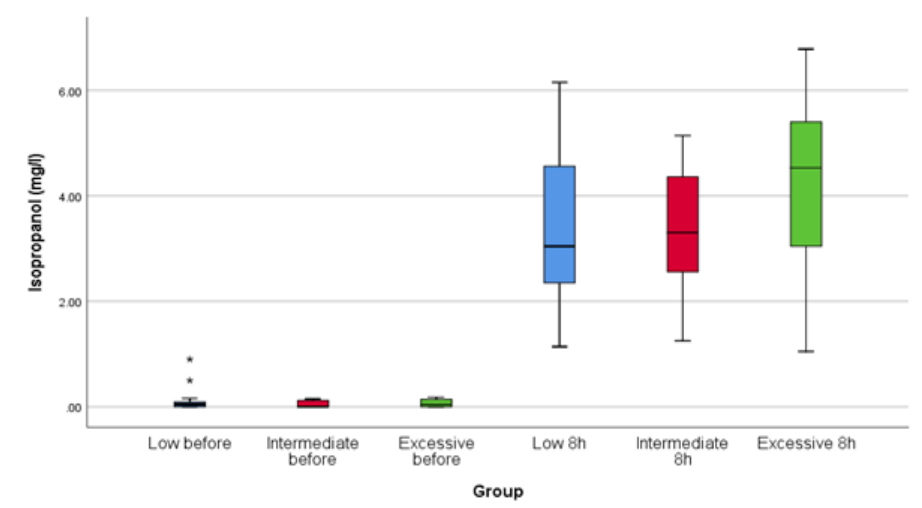

Fig.4: A bar chart showing the medians concentration of ISOP before and 8 hours after ABHSs use in the three groups (low= group I, intermediate $=$ group II, excessive $=$ group III $)$.

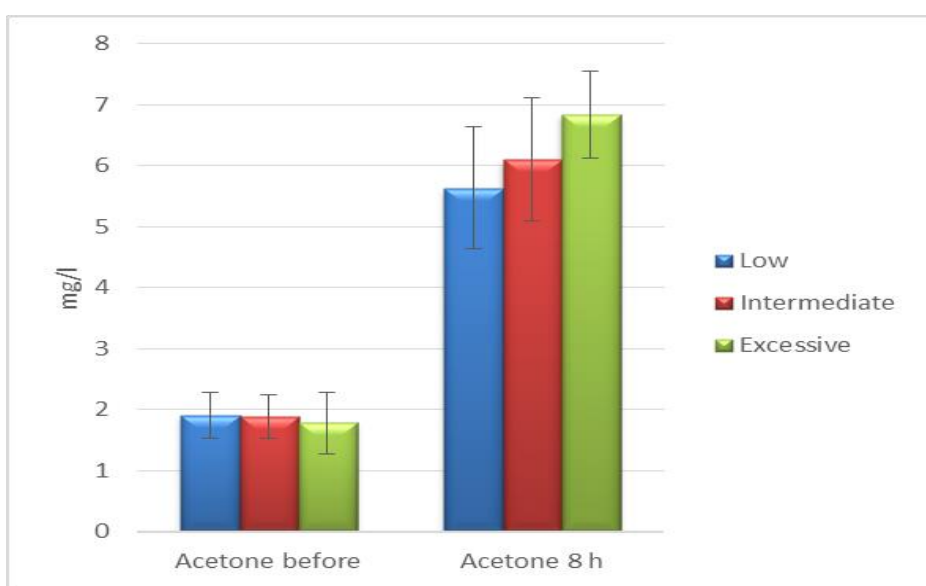

Fig.5: A bar chart showing the median acetone concentrations before and 8 hours after ABHSs use in the three groups $(l o w=$ group $I$, intermediate $=$ group II, excessive $=$ group III).

\section{Discussion}

During hand rubbing, HCWs are exposed to different types of alcohols (e.g., ethanol, ISOP and n-propanol) via inhalation and dermal contact (Bessonneau et al., 2010). The number of ABHSs used varies markedly, depending on the nature of the clinical activity, the hospital setting, or the HCWs adherence with hands hygiene programs (Pittet et al., 2000).
In this study the absorption of ethanol and ISOP were assessed in HCWs in real exposure to two ABHSs containing both alcohols in different concentrations during regular 8-hours working shift. As regard respiratory and dermal symptoms related to ABHSs use, HCWs in group III complained from respiratory symptoms in the form of irritation, sneezing and cough more significant than group I and II, while 
the three groups complained from dermal symptoms in the form of dryness, redness and itching with the same degree. When the two types of hand sanitizer A and B were compared to each other as regard respiratory symptoms, a non-significant difference was found, while, a highly significant increase in group B (with higher concentration of ISOP 60\%) was found as regard dermal symptoms. This may indicate that, the respiratory symptoms were mainly increased in relation to frequency and quantity of ABHSs regardless the concentration, while the dermal symptoms were prominent in higher ISOP concentration in ABHSs. This may be explained by the greater ISOP dermal absorption which might be attributed to the higher dermal permeability coefficient of ISOP (1,350 $\mathrm{cm} /$ hour) (Below et al., 2012). ABHSs users are exposed to alcohols via both inhalation and dermal routes, as alcohols are volatile organic oxygenated species, water soluble, and highly mobile (INRS, 2007). Cumulative occupational exposures to wellknown irritants, such as ISOP can cause respiratory and dermal irritations (Tonini et al., 2009).

These results were consistent with Larson et al. (2006) who stated that approximately $25 \%$ of nurses reported symptoms or signs of dermatitis on their hands, and $85 \%$ gave a history of skin problems and reported that frequent and repeated use of hand hygiene products are an important cause of chronic irritant contact dermatitis among HCWs. Frequent hand washing with lipid-dissolving alcohols, progressively depletes surface lipids, then penetrate into the superficial skin layers leading to skin damage (Kownatzki, 2003). Furthermore, Cartner et al. (2016) compared the effects of three different alcoholic formulations on skin, over 2 weeks, applied daily at standard application rates (20 times per day) and reported that ISOP caused significant skin damage whereas ethanol did not.

\section{Assessment of ethanol absorption:}

EtG and EtS were measured additionally to ethanol in urine because they are excreted in urine about 60 minutes after alcohol consumption and can be detected up to 24 hours even after consumption of small quantities, therefore, EtG and EtS in urine are the short term biomarkers with leading sensitivity (Andresen-Streichert et al., 2018).

The base line values of ethanol which was below the maximum physiological level of $0.32 \mathrm{mg} / \mathrm{L}$ (Kramer et al., 2007) and the undetectable EtG and EtS indicated that, the participants abstained from ethanol before and during the study. The median of the maximum ethanol concentrations in urine were achieved at $8^{\text {th }}$ hour and returned to baseline levels at 16th hour after the first ABHSs use. The median of the maximum EtG and EtS concentrations in urine were achieved at $12^{\text {th }} \mathrm{h}$ and returned to baseline levels at $24^{\text {th }}$ hour after the first ABHSs use. The return of the concentrations of ethanol, EtG and EtS to base line at the $24^{\text {th }} \mathrm{h}$ samples (taken just before the new working shift) meaning that no accumulation of ethanol or EtG or EtS were detected. The only source of alcohol was the ABHSs, this was suggested by the moderate initial increase of ethanol and its metabolites during the morning hours and the maximum increase at the end of the 8 hours shift.

The findings of the current study are in accordance with Gessner et al., 2016 who investigated the kinetics of HCWs' urinary ethanol concentrations and its metabolite EtG during work with abstinence of alcoholic beverages and reported a median maximum ethanol concentration of $0.7 \mathrm{mg} / \mathrm{L}$ (maximum of $9.2 \mathrm{mg} / \mathrm{L}$ ) at the 10th hour and EtG median maximum concentrations of $230 \mathrm{ng} / \mathrm{mL}$ (maximum of $958 \mathrm{ng} / \mathrm{mL}$ ) at the 12th hour, with a non significant correlation between the frequency of alcoholic hand antisepsis with both ethanol and EtG in urine. In the previous study, the highest published ethanol and EtG concentrations were lower than that measured in the current study, this may be due to: first; variation in inhaled exposure because of the air conditioning, concentration of ethanol in air, the duration of exposure, breathing rate, absorption of ethanol across the lungs, and the physiological elimination rate of ethanol. Second; variation in ethanol absorption characteristic from skin and mucous membrane and an individual hand antisepsis action. Third; calculation of the medians to all HCWs with no respect to wide variation in frequency of use which in turn gave low medians. Furthermore, Kramer et al., (2007) measured a maximum median ethanol concentration in blood of $20.95 \mathrm{mg} / \mathrm{L}$ after 20 hand hygiene actions with $4 \mathrm{~mL}$ of ABHSs in a 30-minute period, the medians concentrations were correlated to the hand rubs' ethanol concentrations, they concluded that the amount of ethanol absorbed after repeated applications ranged from $0.9 \%-2.3 \%$ of the amount applied on hands. In the current study a non-significant difference were recorded between the two hand rubs used type A (80\% ethanol) and B (65\% ethanol) as regarded urinary ethanol concentrations, this probably due to the measurement of ethanol in urine. The average ratio of ethanol concentrations in urine and blood is 1.3:1.6 (Bessonneau et al., 2010). On the same way, Pires et al. (2017) who performed serial urinary concentrations of ethanol and EtG in HCWs at the beginning of an 8hour working shift and for the following 24 hours reported that; HCWs performed $32 \pm 12$ hand hygiene actions during a working shift using $3-4 \mathrm{~mL}$ of ethanol based hand sanitizer (96\%), the median of the maximum ethanol concentration in urine was urine was $0.7 \mathrm{mg} / \mathrm{L}$ (IQR, 0.5-1.9 mg/L). Rosano \& Lin (2008) reported that with repetitive daily dermal exposure to hand sanitizer (60\% ethanol) $1 \mathrm{ml}, 20$ times daily for 5 consecutive days by 9 adults, EtG concentration ranged from $<10$ to $114 \mu \mathrm{g} / \mathrm{L}$.

On the other hand, Rohrig et al. (2006) recorded that urinary ethanol was not detected and urinary EtG never exceeded $62 \mathrm{ng} / \mathrm{mL}$ in 9 subjects who cleansed their hands with Germ-X ${ }^{\mathrm{TM}}$ hand sanitizer (62\% ethanol; volume not specified) for a single 8-h day every 15, 30, 60 minutes, the urine samples was collected at 4 hours interval throughout the workday. This study was limited by; first, the relatively small sample size, second, ethanol and EtG were assessed till the end of the 8 hours shift while no data were recorded about the levels changes after that 
as it might increase as the current study where the maximum EtG concentrations were achieved 12 hours after ABHSs first use.

Assessment of ISOP absorption:

The endogenous level of ISOP depends mainly on diet and disease states, it is elevated in alcoholics, starvation and low-calorie diet which favors reduction of acetone to ISOP (Below et al., 2012), these conditions are excluded in the current study. Acetone is the most abundant endogenous volatile organic compound in humans generated during ketogenesis from fatty acid breakdown (Jones, 2000), in the current study.

At the $8^{\text {th }}$ hour both blood ISOP and acetone concentrations increased in the three groups with a significant maximum increase in group III. The blood ISOP levels were dependent on the amount of ABHSs used, while blood acetone levels were dependent on the frequency. Both parameters were independent of the type of hand rub used.The results of the current study are consistent with Below et al. (2012) who measured peak median blood ISOP levels of $5.3 \mathrm{mg} / \mathrm{L}$ after hygienic hand rubs and $10.0 \mathrm{mg} / \mathrm{L}$ after surgical hand rubs, and stated that; only minimal amounts of ISOP are absorbed through the use of hand rubs, ethanol has less toxicity and lower dermal absorption than ISOP, and more easily metabolized by ADH. Furthermore, Turner et al. (2004) reported measurable blood ISOP levels (range $0.5-1.8 \mathrm{mg} / \mathrm{l}$ ) in nine subjects of ten healthy adult volunteers applied an ISOP-containing hand rub to their hands every 10 min over a $4 \mathrm{~h}$ period. The measured levels in the current study are more than that measured by Turner et al. (2004) who had a small sample size only 10 participant using hand sanitizer containing only ISOP for only 4 hours.

On the other hand, Brown et al. (2007) reported undetectable serum ISOP level after 10 to 13 min post exposure in $20 \mathrm{HCWs}$ used ABHSs 30 times during a $1 \mathrm{~h}$ period. This study had the following limitations; the routine alcohol consumption of the HCWs was not assessed as well as the intensive ABHSs were used for only $1 \mathrm{~h}$. Elevated urinary acetone is a possible marker of exposure to ISOP (Below et al., 2012). ISOP is converted into acetone by oxidation with class I isoenzymes of hepatic alcohol dehydrogenase, Then it is mainly excreted unchanged in breath and urine and to some extent oxidized by cytochrome P450-enzymes, but this is a relatively slow detoxification mechanism (Jones, 2000).

EtG and EtS cut offs:

In the current study, at $12^{\text {th }}$ hour post ABHSs first use; all participants had a maximum urinary EtG levels $\geq 100 \mathrm{ng} / \mathrm{ml}$ while, 30 (40.5\%) of them had urinary EtG levels $\geq 500 \mathrm{ng} / \mathrm{ml}$ (7 subjects in group I, 4 subjects in group II and 19 subjects in group III) and no subject exceeds the $1000 \mathrm{ng} / \mathrm{ml}$. EtS was detected in fewer subjects than EtG, it was not detectable in 21 participants (28.4\%). One participant (1.3\%) had EtS level of $34 \mathrm{ng} / \mathrm{ml}, 52$ participants (70.3\%) had levels $\geq$ $50 \mathrm{ng} / \mathrm{ml}$ while no participant exceeded $100 \mathrm{ng} / \mathrm{ml}$. The urinary EtG and EtS levels were correlated to the frequency and the amount of ABHSs used but not to urinary ethanol levels.
The results of the current study were consistent with Salomone et al. (2018) who analyzed EtG in urine after ABHSs use by one subject for 20 times a day, for 4 consecutive weeks, simulating a workplace situation, the data obtained showed a significant absorption of ethanol which produced urinary EtG concentrations higher than the cut-offs normally used for clinical and forensic analyses (either 100 and $500 \mathrm{ng} / \mathrm{ml}$ ) and concluded that the continuous use of alcohol-based hand disinfectants can lead to a positive EtG in urine. Furthermore, Reisfield et al. (2011) measured urinary EtG and EtS following sustained application of hand sanitizer (62\% ethanol) every 5 min for 10 hours in three consecutive days, the urine specimens were obtained at the beginning and end of each day of the study and reported that, 72.7\% produced urinary EtG concentrations above $500 \mathrm{ng} / \mathrm{ml}$; 46.4\% produced EtG concentrations above $1000 \mathrm{ng} / \mathrm{ml}$; and $9 \%$ produced urinary EtG concentration exceeding $2000 \mathrm{ng} / \mathrm{mL}$, while no subject produced a urinary EtS $\geq 100 \mathrm{ng} / \mathrm{ml}$. Apart from oxidative metabolism, the phase II metabolite EtG $(0.02-0.06 \%$ of the ingested alcohol) and EtS (0.010-0.016\%) are created from alcohol to a minor extent (Andresen-Streichert et al., 2018). Sulfation of ethanol may be a pathway that produces significant quantities of EtS only when the ethanol concentration is high enough to saturate alcohol dehydrogenase and glucuronosyl transferase pathways, this may explain the participants with positive EtG and negative EtS, thus it is better to measure both EtG and EtS as it might be useful in discriminating between ethanol consumption and incidental exposure to ethanol-containing products (Reisfield et al., 2011).

On the other hand, Gessner et al. (2016) reported a relative independency of the EtG concentration and the number of hand antisepsis actions. Levels of EtG can vary dramatically between individuals who consume the same amount of alcohol as much as 200 fold, there are likely individuals in the population that are "hyperproducers" of EtG and have much higher levels following exposure to alcohol, including incidental exposure (SAMHSA, 2012). This is because of the variation in the genetic polymorphism of the enzyme UDP-glucuronosyl-transferase which is responsible for the process of glucuronidation, a major part of phase II metabolism (Gessner et al., 2016).

The sensitivity EtG and EtS in urine depends on alcohol quantity, time interval between sample collection and alcohol intake as well as the cut-off level of the method applied, however, the disadvantage of the very high sensitivity of this method is that the EtG/EtS levels in urine do not allow to distinguish between a binge drinking event several days ago and a potentially minor alcohol exposure as highly concentrated ethanol-based disinfection solutions (6096\%) (Andresen-Streichert, et al., 2018). Most monitoring programs use empirically adjusted upper limits of 500 or $1000 \mathrm{ng} / \mathrm{mL}$ for EtG in urine, above which incidental exposure is ruled out the [Substance Abuse and Mental Health Services Administration (SAMHSA) Advisory (2012)]. Unlike EtG, EtS cutoffs are not yet universally agreed upon while, the proposed 
cutoff value for EtS ranges from 50 to $200 \mathrm{ng} / \mathrm{ml}$ (Albermann et al., 2012).

\section{Conclusion}

From the results of the current study we can conclude that, the repeated application of ABHSs in HCWs' daily routine generates measurable levels of ethanol and its metabolites EtG and EtS in urine as well as ISOP and its metabolite acetone in blood which indicated the absorption of ethanol and ISOP and their subsequent degradation with rapid decrease of their concentrations to baseline levels within 24 hours (not accumulated). These parameters were positively correlated to frequency and quantity of ABHSs used.

The measured blood ISOP concentrations were below the toxic levels in humans. EtG was the only parameters correlated positively to the concentration of ethanol in ABHSs. Not only the excessive use of ABHSs but also low and intermediate exposures produced urinary EtG concentrations that exceeded $500 \mathrm{ng} / \mathrm{ml}$ while, EtS concentrations did not exceed $100 \mathrm{ng} / \mathrm{ml}$ in all use mood. The EtG threshold of $1000 \mathrm{ng} / \mathrm{ml}$ and EtS threshold of $100 \mathrm{ng} / \mathrm{ml}$ seemed to be more promising to distinguish between intentional ethanol use and incidental exposure to ethanol based hand sanitizers. Measuring EtS with EtG might be useful in identification of incidental exposure to ethanol hand sanitizers.

\section{Recommendations}

From the results of the current study, ABHSs in HCWs can produce urinary concentrations of EtG that, by current standards, may be interpreted as intentional ethanol use so, further studies are needed to confirm the cut offs recommended in this study to distinguish between intentional alcohol intake and incidental ethanol exposure in HCWs. With the growing interest in Egypt to the employees' screening for drug of abuse, it is thought that urinary EtG may be added to the screening tests, in this case an occupations as HCWs using ethanol incidentally will benefit from the cut off settings to avoid false accusations. With exposure to alcohols mainly via inhalation further researches are recommended to determine contamination levels of alcohols especially ISOP in the environment of HCWs' workplace.

It is also recommended to conduct large scale studies on certain vulnerable individuals such as pregnant women, individuals with known liver disease or alcohol dehydrogenase and/or aldehyde dehydrogenase genetic deficiencies for risk assessment.; assess the potential adverse effects caused by long-term exposure to ABHSs, especially that contains ISOP.

\section{References}

Albermann, ME, Musshoff, F and Madea, B (2012): A High-Performance Liquid ChromatographicTandem Mass Spectrometric Method for the Determination of Ethyl Glucuronide and Ethyl Sulfate in Urine Validated According to Forensic Guidelines. Journal of Chromatographic Science. 50(1):51-56.

Andresen-Streichert, H, Müller, A, Glahn, A, et al. (2018): Alcohol Biomarkers in Clinical and
Forensic Contexts. Deutsches Ärzteblatt International Dtsch Arztebl Int. 115(18): 30915.

Arndt, T, Schröfel, S, Güssregen, B, et al. (2014): Inhalation but not transdermal resorption of hand sanitizer ethanol causes positive ethyl glucuronide findings in urine. Forensic Sci Int. 237:126-30.

Baranowski, S, Halter, CC, Serr, A, et al. (2008): In vitro study of bacterial degradation of ethyl glucuronide and ethyl sulfate. Int J Legal Med.122(5):389-93.

Below, H, Partecke, I, Huebner, NO, et al. (2012): Dermal and pulmonary absorption of propan1-ol and propan-2-ol from hand rubs. American Journal of Infection Control. 40(3): 250-7.

Bessonneau, V, Clément, M and Thomas O (2010): Can Intensive Use of Alcohol-Based Hand Rubs Lead to Passive Alcoholization?. Int J Environ Res Public Health. 7(8):3038-50.

Bolon MK (2016): Hand hygiene: An update. Infect Dis Clin North Am. 30(3):591-607.

Brown, TL, Gamon, S, Tester, P, et al. (2007): Can Alcohol-Based Hand-Rub Solutions Cause You To Lose Your Driver's License? Comparative Cutaneous Absorption of Various Alcohols. Antimicrobial Agents and chemotherapy. 51(3):1107-08.

Cartner, T, Brand, N, Tian, K, et al. (2017): Effect of different alcohols on stratum corneum kallikrein 5 and phospholipase A2 together with epidermal keratinocytes and skin irritation. International Journal of Cosmetic Science. 39(2):1-9.

Centre for Health Protection (2017): Guidelines for hand hygiene. Available at: https://www.chp.gov.hk/files/pdf/guidelines_f or_hand_hygiene.pdf.

Chan, P and Chan, Y (2018): Methanol as an unlisted Ingredient in Supposedly Alcohol-Based Hand Rub Can Pose Serious Health Risk. Int J Environ Res Public Health. 15(7):1440.

Dahl, H, Stephanson, N, Beck, O, et al. (2002): Comparison of urinary excretion characteristics of ethanol and ethyl glucuronide. J Anal Toxicol. 26(4): 201-4.

Gessner, S, Below, E, Diedrich, S, et al. (2016): Ethanol and ethyl glucuronide urine concentrations after ethanol-based hand antisepsis with and without permitted alcohol consumption American Journal of Infection Control. 44(9): 999-1003.

Goll, M, Schmitt, G, Ganssmann, B, et al. (2002): Excretion profiles of ethyl glucuronide in human urine after internal dilution. J Anal Toxicol. 26(5): 262-6.

Helander, A, Olsson, I and Dahl, H (2007): Postcollection synthesis of ethyl glucuronide by bacteria in urine may cause false identification of alcohol consumption. Clin Chem. 53(10):1855-7. 
Institut National de Recherche et de Sécurité (INRS) (2007): Ethanol; fiche toxicologique FT 48; INRS: Paris, France.

Jones, AW (2000): Elimination Half-Life of Acetone in Humans: Case Reports and Review of the Literature. Journal of Analytical toxicology. 24(1):8-10.

Kownatzki, E (2003): Hand hygiene and skin health. J Hosp Infect. 55(4): 239-45.

Kramer, A, Below, H, Bieber, N, et al. (2007): Quantity of ethanol absorption after excessive hand disinfection using three commercially available hand rubs is minimal and below toxic levels for humans. BMC Infectious Diseases. 7:117.

Larson, E, Girard, R, Pessoa-Silva, CL, et al. (2006): Skin reactions related to hand hygiene and selection of hand hygiene products by the Association for Professionals in Infection Control and Epidemiology, Inc. 34(10): 635727.

Litten, RZ, Bradley, AM, and Moss, HB (2010): Alcohol biomarkers in applied settings: Recent advances and future research opportunities. Alcoholism: Clinical and Experimental Research. 34(6):955-967.

Maier, A, Ovesen, LJ, Allen, LC, et al.(2015): Safety assessment for ethanol-based topical antiseptic use by health care workers: Evaluation of developmental toxicity potential . Regulatory Toxicology and Pharmacology. 73(1): 248-64.

Pires, D, Bellissimo-Rodrigues, F and Pittet, D (2017): Ethanol-based handrubs: Safe for patients and health care workers . American Journal of Infection Control. 44(8): 858-9.

Pittet, D, Hugonnet, S, Harbarth, S, et al. (2000): Effectiveness of a hospital-wide program to improve compliance with hand hygiene, Infection Control Program. Lancet. 356(9238):1307-12.

Reisfield, GM, Goldberger, AB, Crews, OB, et al. (2011): Ethy lGlucuronide, EthylSulfate, and
Ethanol in Urine after Sustained Exposure to an Ethanol-Based Hand Sanitizer. Journal of Analytical Toxicology. 35(2):85-91.

Roemhild, W, Krause D, Bartels, H, et al. (1998): Congener analysis by means of "headspace" GC/MS. Blutalkohol. 35(1):10-8.

Rohrig, TP, Huber, C, Goodson, L, et al. (2006): Detection of ethylglucuronide in urine following the application of Germ-X. J Anal Toxicol. 30(9):703-4.

Rosano, TG and Lin, J (2008): Ethyl glucuronide excretion in humans following oral administration of and dermal exposure to ethanol. J Anal Toxicol. 32(8): 594-600.

Salomone, A, Bozzo, A, Corcia, D, et al. (2018): Occupational Exposure to Alcohol-Based Hand Sanitizers: The Diagnostic Role of Alcohol Biomarkers in Hair. Journal of Analytical Toxicology. 42(3):157-162.

Substance Abuse and Mental Health Services Administration (SAMHSA) advisory (2012): The role of biomarkers in the treatment of alcohol use disorders. HHS Publication No. (SMA) 12-4686, First Printed 2006, Revised 2012. 11(2):1-8.

Tonini, S, Dellabianca, A, Costa, CM, et al. (2009): Irritant vocal cord dysfunction and occupational bronchial asthma: differential diagnosis in a health care worker. Int J Occup Med Environ Health. 22(4), 401-406.

Turner, P , Saeed, B, and Kelsey, MC (2004): Dermal absorption of isopropyl alcohol from a commercial hand rub: implications for its use in hand decontamination. $\mathrm{J}$ Hosp Infect. 56(4):287-90.

World Health Organization (WHO) (2009): Guidelines on Hand Hygiene in Health Care. First Global Patient Safety Challenge: Clean Care is Safer Care; WHO: Geneva, Switzerland,. Available at:

http://whqlibdoc.who.int/publications/2009/97 89241597906_eng.pdf. 


\section{الملخص العربي}

المؤشرات الحيويه لامتصاص الكحوليات نتيجة الاستخدام المستمر لمطهرات اليدين في افراد الرعاية الصحية: المستوي المرجعي للايثيل جلوكورونيد و الايثيل سلفات

\section{غادة نبيل منصور ا و دينا سامع الرفاعيr}

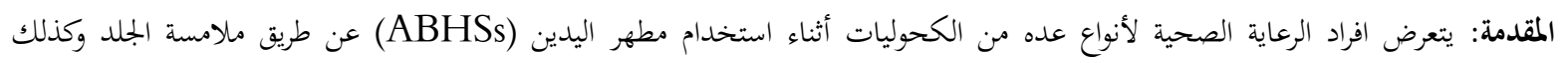

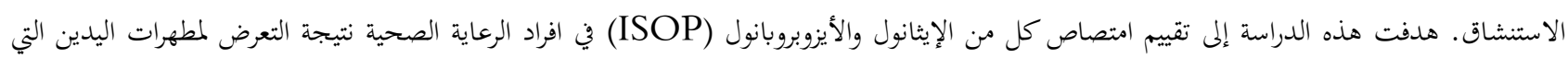

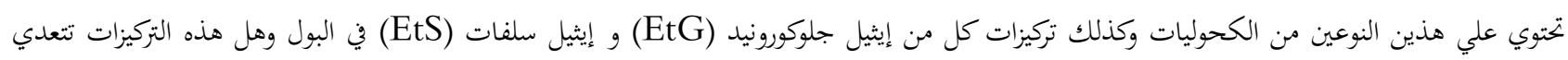

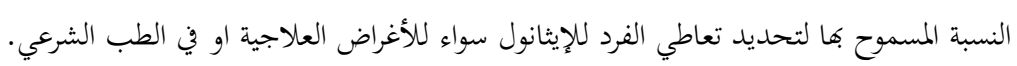

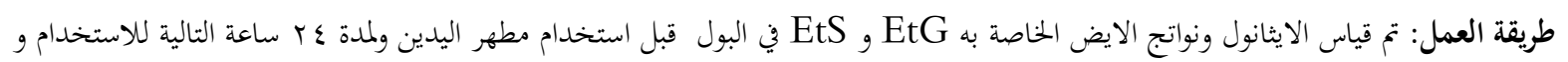

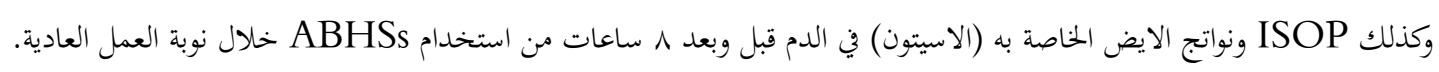

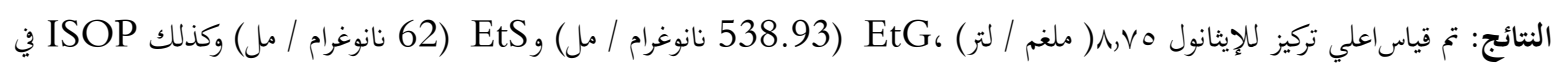

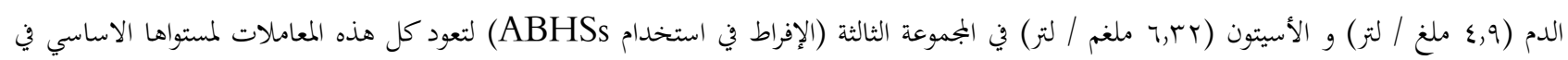

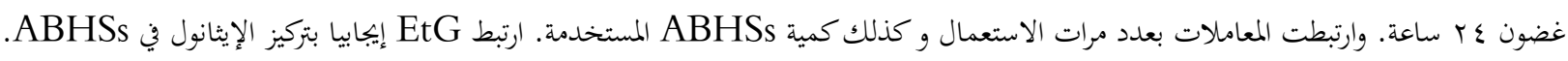

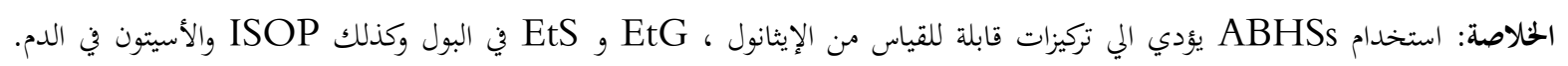

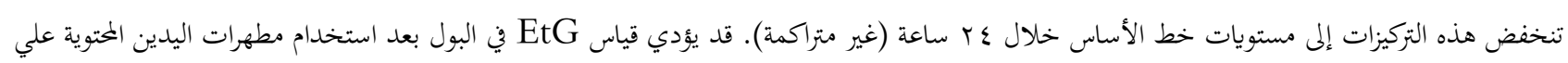

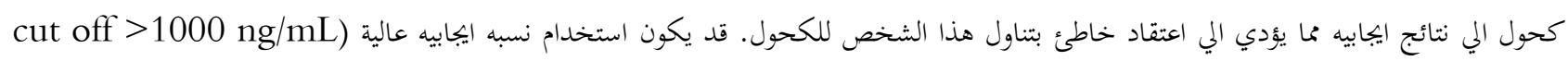
(EtG

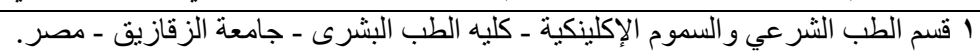
r ب قسم الصحة العامة و البيئة وطب الصناعات_كلية الطب- جامعة الزقازيق - مصر. 